\title{
Managing sexual difficulties: A qualitative investigation of coping strategies
}

\begin{abstract}
Biomedical interventions offer effective treatment for only a small proportion of individuals experiencing sexual difficulties. Where treatment fails, individuals have to find ways to cope and adjust. We currently know little about how they do this. We present data from 32 semi-structured interviews with individuals representing a range of sexual function experience. We identified three broad coping approaches. The first, changing circumstances to fit goals, included strategies such as seeking biomedical treatment and ending a relationship. The second approach, changing goals to fit circumstances, included strategies such as changing one's definition of good enough sex. The final approach, living with a gap between goal and circumstances, included strategies such as normalising and avoiding the problem. Several factors appeared to be key in determining successful adjustment: the severity of the problem; causal attributions made about the problem; and the partnership context. We explain our findings in terms of Brandstadter's distinction between accommodative and assimilative coping strategies, and suggest that a flexible definition of good enough sex, as well as a flexible stance towards the importance of sex may enhance the process of adjustment.
\end{abstract}


Sexual function problems are common in the UK. Roughly $6 \%$ of men and $16 \%$ of women reported at least one persistent ${ }^{\mathrm{i}}$ sexual function problem in a recent national survey (Mercer et al., 2003). And in a recent study of General Practitioner (GP) attendees, $22 \%$ of men and $40 \%$ of women received at least one ICD-10 diagnosis for sexual dysfunction (Nazareth, Boynton, \& King, 2003). Sexual difficulties often involve profound and complex personal and relationship issues (Metz \& McCarthy, 2007). In the short term these difficulties can cause frustration and distress; in the longer-term, problems may lead to anxiety, depression, harmed relationships and disruptions to other areas of life (Arrington, Confrancesco, \& Wu, 2004).

Around $20 \%$ of men and $32 \%$ of women with persistent sexual difficulties seek help. The majority of those seeking help (64\% of men and $74 \%$ of women) turn to their GP (Mercer et al., 2003). Often, there is not much that GP's can offer their patients; despite significant funding and interest from the pharmaceutical industry, development of pharmacological treatments (with the exception of PDE-5 inhibitors) has been modest (Levine, 2007; Balon, 2007). Particularly for women, effective treatment consists, not in a narrowly focused medical intervention, but rather in addressing the "depressingly complex causes" (Goldacre, 2007, p. 932). The study by Mercer and colleagues also implies that the majority of individuals respond to their sexual difficulties without seeking formal help. To what extent do these individuals cope and adjust? What coping strategies do they employ?

There are several reasons for seeking to understand the variation in responses to sexual difficulties. Firstly, we may gain insights into the apparent paradox that only a proportion of

\footnotetext{
${ }^{\mathrm{i}}$ Defined as occurring for 6 months or more.
} 
those with sexual difficulties are distressed by them (Mitchell \& Graham, 2008). Secondly, an exploration of coping responses may help in understanding why some individuals respond well to pharmaceutical treatment or therapy while others do not. Thirdly, despite a considerable psychological literature on coping, little empirical work has been conducted specifically on coping with sexual difficulties.

The definition of coping adopted here is "the cognitive processes whereby the individual learns how to tolerate or put up with the effects of illness ... [which] involves maintaining a sense of value and meaning in life" (Bury, 1991, p. 460-461). Because there is only a moderate association between sexual dysfunction and individually perceived distress, our investigation is not restricted to clinically diagnosable dysfunction but looks at the ways in which individuals and couples respond to a sex life that fails to meet their personal definition of 'good enough' sex. We use the term 'good enough' because it allows for the possibility of satisfaction without the expectation of perfection. The term is used to describe parenting (Swain \& Cameron, 2003), to describe governance (Grindle, 2007), and is already in use in sexology (Metz \& McCarthy, 2007). Whereas the term 'ideal' may describe a theoretical goal, 'good enough' describes an achievable goal.

\section{Method}

This paper reports on data from a larger qualitative study whose overall aim was to explore the meaning of sexual (dys)function to those with and without experience of sexual problems. The aim of this section of the study was to identify the range of different coping responses to sexual difficulties. In order to capture a wide range of sexual function experience we recruited 
individuals from three groups: first, those who self-identified as having sexual difficulties $(\mathrm{n}=6$; consecutive patients attending a National Health Service (NHS) sexual problems clinic in London); second, those with conditions associated with sexual difficulties (selected randomly from the diabetes patient list and depression patient list of a GP surgery in London and invited to participate by letter $(n=13)$ and from an HIV charity in a regional town $(n=3))$; and third, a community group of consecutive attendees at the same GP surgery, recruited from the waiting room $(\mathrm{n}=10)$. The first group consisted of those whose experience of sexual difficulties had driven them to seek help; the second group comprised individuals who, because of their underlying health problems (diabetes, depression and HIV), were likely to be experiencing some problems but not necessarily to have sought help for them or to have self-identified as having difficulties (sub-clinical); the third group represented a proxy to a general population sample, with some individuals experiencing difficulties and others not. Non-English speakers and those under the age of 18 were excluded. The final sample had representation from key demographic groups of interest.

Interviews of between 45 minutes and two hours duration were carried out by KM (30) and KW (2) and audio-taped (with permission). The discussion was framed by a topic guide that sought to facilitate participants' accounts of their personal experiences. Open-ended questions probed the various ways in which participants envisaged a satisfactory sex life and what they saw as problematic and non-problematic for themselves. For those who described any sexual concern or problem ( $\mathrm{n}=25$ ), further discussion explored the impact of that problem on their lives (see Box One). The discussion was followed by a card exercise in which participants were presented with 16 numbered cards each describing a different sexual difficulty, (for instance, 'Experiencing 
physical pain on intercourse' and 'Not feeling sexually satisfied'). Participants were asked to place each card in one of four piles: 'Just the way life is', 'A problem but not one that is big or worrying', 'A serious problem', and 'Don't know/depends'. Participants were encouraged to think aloud as they sorted the cards and the exercise was followed by a discussion about their decisions. Individual categorisations were recorded and the results pooled to provide an overall ranking of difficulties in terms of their perceived severity. This exercise served primarily as a discussion primer and was particularly useful in interviews where participants had not encountered any difficulties themselves. It also enabled triangulation of personal accounts with more hypothetical judgments about the severity of problems.

In this paper we describe the results of the section of the interview that explored how participants responded to their difficulties.

[Box One about here]

The interviews were transcribed verbatim and the transcripts checked as part of the familiarisation process (this is a preliminary stage in which the analyst becomes familiar with the range and diversity of the full data set (Green, 2005)). Careful consideration of the narrative told by each individual enabled subjective categorisation of participants according to their experience of sexual difficulties (see Table One). Individuals who did not describe any significant frustration or difficulty were categorised as 'functional'; those who expressed minor frustrations and/or difficulties but no significant concern about these experiences were categorised as 
'dissatisfied'; and those who described significant problem(s), some level of distress and had also either sought or considered clinical help were categorised as 'problematic'.

[Insert Table One about here]

Initially the data (interview transcripts) were catalogued according to broad themes (such as orgasm, satisfaction and frequency) and entered into an excel spreadsheet (Ritchie \& Lewis, 2003) (also see http://www.framework-natcen.co.uk/) which served as a data retrieval tool.

Once the data had been mapped thematically, we carried out more detailed interpretative analysis on the specific theme of responding to difficulties/coping. At this stage we borrowed some of the key principles of Grounded Theory (Strauss, 1987); a set of principles and practices that seek to generate theoretically dense accounts 'grounded' in empirical data (Green \& Thorogood, 2004). Taking whole excerpts on the theme of responding to difficulties, we undertook line-by-line analysis (open coding) to generate codes (a conceptual label for a piece of data, for example, 'changing goals to fit circumstances'). We then explored the dimensions of codes (sometimes known as axial coding). For instance, for the code 'changing goals to fit circumstances', one of the dimensions identified was 'engage flexible stance towards the importance of sex'. Axial coding resulted in a dense framework of inter-linked categories. The final typology emerged through an iterative and dynamic process involving movement back and forth between data and theory. Throughout, we used 'experiential data' (technical knowledge plus the experience of the analyst) and discussion between authors (KM and KW) to guide coding decisions, and we sought 
out data (quotes/text) that would both confirm and challenge our emerging classification (Strauss \& Glaser, 1975).

\section{Results}

\section{Coping Strategies}

Table Two summarises the coping strategies identified from participant accounts.

[Insert Table Two about here]

Within the 'dissatisfied' and 'problematic' groups, initial reactions to sexual difficulties included shock, confusion, worry and embarrassment. With time, many of the participants whose sex life did not match their ideal adjusted to this situation by adopting one or more of the coping strategies described in Table Two. We explore each strategy in detail below.

Changing Personal Circumstances to Fit Goals. This approach implied seeking to 'fix' problems such that an ideal or 'good enough' version of sex could be achieved. The principal strategy for fixing the problem was to seek professional help. Ten participants relayed their experiences of doing this. In around half of these accounts, action was prompted or strongly supported by the sexual partner. In several instances, the partner was keen to find a solution but the individual seen as having the main problem was reluctant to do so. Embarrassment, feelings 
of failure and the belief that sexual matters are private were cited as deterrents to seeking formal help:

(Help-seeking): I couldn't [seek help] straight away because it was that sort of subject. It was accepting defeat in a man so to speak (Man aged 65-69).

Seeking help was regarded as more appropriate for problems with a perceived physical, rather than psychological, aetiology. The former were regarded as easier to solve, whilst the latter were seen as more appropriately tackled within the relationship.

Changing personal circumstances did not always imply professional help. Reports of self-cures included working (without professional help) to overcome a physically repressed upbringing (one participant), and ending the relationship perceived to be associated with the difficulty (several participants).

Not all difficulties were easily overcome. PDE5 inhibitors had failed at least two participants and penile injections were seen as inconvenient and intrusive by the one male participant using them. Neither of the two individuals experiencing sexual pain had found much relief for their symptoms. And ending a relationship was not necessarily seen as desirable, particularly where children or other commitments were involved. Thus, other coping strategies came into play.

Changing Goals to Fit Personal Circumstances. Several participants relegated sex to a lower priority as a means of coping with potentially problematic sexual experiences. For example, one 
man (aged 35-39) who had experienced loss of desire whilst taking anti-depressant medication, described his "sex drive" at the time as of "absolutely secondary importance" compared with his wish to recover from depression, and thus did not consider the loss of desire to be problematic.

(Relegating sex to a lower priority): You put the sexual thing away really and just get on with your life. At that point I decided that my main thing was to make sure that the children were secure... (Woman aged 60-64)

Motivations to redefine sex as a lower order concern may be multi-layered. For instance, the woman quoted above described how, for the benefit of her children, she had remained in an unsatisfactory sexual relationship with their father by putting "the sexual thing away". But her account also revealed several other reasons for relegating sex: self-defence (protecting herself from possible hurt caused by the relationship); because of circumstance (there were few opportunities in terms of other partners); and because of a change in priority with age (other aspects of the relationship had become more important).

Several participants described lowering their expectations as a result of their current circumstances, in recognition of the fact that a balance was needed between competing personal needs. A commonly described compromise was between physically good sex and a good interpersonal relationship. Particularly among women, the latter was often rated as more important: 
(lowering expectations): If I had a strong relationship with someone, in terms of getting on with them and all various things, and sex wasn't that great it wouldn't bother me. (Woman aged 30-34).

For an HIV positive woman, the need to have sex without fear of infecting a partner outweighed the need for physically ideal sex. She was prepared to forgo the latter in order to have the former.

(Lowering expectations): He took away from me that fear of infecting somebody.

So I was able, in some ways, to enjoy the sex even though it wasn't that good. (Woman aged 40-44).

The need for compromise was felt to be particularly acute during the stage of life in which people looked to settle down and perhaps raise a family. For example, a bisexual man (aged 7579) described how he had given up his sexual relationships with men in order to become faithfully married because what he wanted was stability and respectability. Although his married sex life was unsatisfactory, it "wasn't the end of the world" for him because he had gained the other benefits of a stable relationship. Among several participants there was almost an expectation that physically enjoyable sex would be sacrificed on the altar of 'grown up' responsibilities.

There was evidence that if personal circumstances necessitated, it was possible to adjust definitions of good-enough sex. For instance, an HIV positive male participant who feared infecting his partner had re-defined good-enough sex to prioritise safer activities. Another man in 
his early sixties shifted his definition of good-enough sex to focus on "the processes leading up to [intercourse]" because ejaculation had become painful:

(Flexible definition of good enough sex): Perhaps I'm wrong but I accept the fact that the diabetes reduces my libido and that I'm not going to come to orgasm as often as I would if I didn't have the diabetes; but that I can have sex and enjoy the physical sex without the orgasm if I take the medication. It's the situation I find myself in. (Man aged 60-64)

With increasing age, several of the older participants reported a shift in emphasis towards intimacy, giving less prominence to penetration. This appeared to be an adaptive shift, enabling them to continue to enjoy sex even where physical function was deteriorating. More often, participants (especially younger ones) found it difficult to alter their definition of good enough sex, particularly when this required shifting from a penetrative to a non-penetrative focus. One man (aged 60-64) with erectile difficulties, was able to adjust to having less regular orgasms, but said that his attempts at trying alternatives to penetration only served to "reinforce [his] feelings of inadequacy". It could be equally difficult to adjust to a sex life devoid of emotional intimacy; a gay man (aged 45-49) experiencing relationship problems felt that masturbation and internet chat rooms provided only "small compensation".

Living with a Gap Between Goals and Circumstances. A less than perfect sex life was generally regarded as normal. This perspective enabled some of those with difficulties to conceptualise their experiences as normal: 
(Normalising): Everyone has problems. I don't know if I know anybody that's ever said they have a perfect sex life... [...]...If someone has I think they're lying!" (Woman aged 30-34).

(Normalising): Interviewer: The fact that [you don't have sex], do you see that as a big problem?

Well I used to but I don't now because I actually think it's quite normal [...]. At first I thought I was abnormal and now I don't believe I am at all. I believe the state I'm in is absolutely quite normal (Woman aged 50-54).

Another strategy adopted by participants was to define dysfunctional in a way that meant that their own experience would not be seen as such; a woman (aged 46-50) with severe vulvodynia viewed her own condition as physical, and defined dysfunction as psychological, thus positioning herself outside of the 'dysfunctional' group. However, normalising one's experience was not always possible or even desired. One man, struggling to cope with his erectile difficulties, described the intrusion of the abnormal into what he otherwise saw as his normal existence:

(Normalising): You never think it's going to happen to you, but it does happen in your normal life. An abnormal life then I can understand it - maybe you would end up drunk and spending the night with someone else. But I had a very steady life - it was going well. (Man aged 65-69) 
In a number of instances, participants coped with a problem by simply avoiding it. Sometimes this avoidance was seen as benign; letting the problem be subsumed within the trials of daily life: "your daily life goes on and you forget that there is this major problem" (Woman aged 60-64). There were also accounts of more problematic avoidance which were recognised (though usually in retrospect) as "storing up the problem for later on" (Man aged 30-34):

(Avoiding): From my own experience, its running away from the problem I suppose and not confronting it (Man aged 30-34)

This man described his attempts to avoid confronting his sexual difficulties. During the early phase of his sexual career he claimed sex was not that important to him. He later recognised this as a story he told himself in order to avoid confronting his lack of enjoyment. More recently, during the early phases of his current relationship, he had used the fact that he and his partner were already long term friends as an excuse to take the sexual side of the relationship very slowly. Again, in retrospect this was “a convenient guise...I didn't have to do very much to avoid having it". Coming to recognise that he did actually have a problem initially involved a feeling of failure but was essential to confronting his difficulties. 
Non Adjustment. Around a third of the participants were still struggling to adjust to sexual lives they rated as 'not good enough'. Despite employing various coping strategies, they continued to perceive a problematic gap between their ideal and their lived reality. A range of affective states were described in association with lack of adjustment, including feelings of rejection, defeat, depression, worry, frustration, apprehension and inadequacy.

Occasionally, these negative feelings were contained within the sexual sphere; but often their effects spilled over into other areas of life. There were several accounts of unresolved sexual difficulties having had a devastating impact on the relationship. For one man (aged 60-64), his erectile failure "was... an important point in the...disintegration of my marriage" and caused a "virtual cessation" of the sexual side of the relationship. Another woman's experience of vulvodynia eventually affected all spheres of life. She described having to give up work, her relationship breaking down and being evicted from her partner's home:

(Non-adjustment): It's thrown my whole life upside down. Tore it to shreds really (Woman aged 45-49).

\section{Factors Influencing Coping}

From the data, we identified several factors that appeared to influence whether or not individuals were able to close the gap between ideal and reality; whether they managed to live with it; or continued to find it problematic. These factors (Table Three) had potential to influence not only 
the choice of strategy, but also the likelihood that the strategy would result in successful adaptation and coping.

[Table Three about here]

Perceived Symptom Severity. It seems reasonable to assume that a problem perceived as severe will be harder to cope with than one perceived as mild. A mild difficulty is more easily constructed as 'normal'; and the required adjustment to expectations only slight. During the interview, participants were shown a set of common difficulties and asked to think about which they would find most problematic for themselves (the card exercise). According to the pooled ranks, three of the problems were clearly viewed as severe: deliberately avoiding sex, erectile difficulties and sexual pain; and three as mild: excessive sexual drive, not feeling interested in sex but enjoying it once it gets going and vaginal dryness.

We identified several dimensions of perceived severity. Firstly, definitions of good enough sex: those who prioritised interpersonal aspects tended to rank relational difficulties most severely while those whose definition of good enough sex centred on physical functioning tended to view physical problems as most severe. Secondly, difficulties perceived as remediable were seen as less severe. For instance, problems associated with vaginal dryness were generally perceived as easy to resolve with lubricant. A third dimension of severity was the duration and frequency of the symptoms. Transient and occasional difficulties were not generally regarded as problematic. There were several instances in which participants described experiences that would have become problematic had they continued over a significant period of time. Finally, severe 
difficulties were seen as those that precluded intercourse or led to further problems (for example, erectile difficulties leading to anxiety).

Causal Attributions. All the participants experiencing sexual difficulties had reflected to some extent on the possible causes of their problem. The attributions they made about their difficulties appeared to impact on the degree of perceived severity. We identified three different types of attribution. The first concerned whether or not the cause of the problem was seen as located within or outside of the relationship. Where the cause was located within the relationship, the danger was that the difficulty was seen to indicate a loss of attraction to a partner, which led to feelings of rejection. Secondly, the degree of culpability appeared important. One man (aged 3034) reported that his partner had blamed herself for his erectile difficulties, feeling that she was not able to excite him sufficiently. This self-blame exacerbated the problem by creating additional pressure on him to demonstrate that she could in fact excite him. They sought professional help, which was partly focused on changing perceptions of the origin of the problem, with immediate effect:

(Causal attributions): I think she's started to see now that [she's] not the root cause of [the problem] which obviously is very reassuring for me and takes some of that pressure off...(Man aged 30-34).

Finally, the extent to which the cause was understood and/or expected appeared to be important. One or two women said they found the changes to their sex life brought about by pregnancy unproblematic because they anticipated and understood the reason for them. In contrast, the 
impact of pregnancy was experienced as problematic by one woman (aged 35-39), whose partner did not understand that being pregnant could influence her desire for sex. He came to feel rejected and continued to pressure her for sex.

Interpersonal Context. Two inter-related aspects of the inter-personal context appeared to influence the level of adjustment to the problem: firstly the strength and quality of the relationship; and secondly the reaction of the partner to the specific problem.

According to many participants, characteristics of a strong relationship included being able to talk openly about difficulties, and being able to confront problems rather than letting them drift ("If I was with a loving partner, I would not let the problem go on"; Woman aged 60-64); being able to discuss problems in ways that avoided creating discord ("Depending on how close the couple is you can kind of laugh it off"; Woman aged 25-29); and avoiding blame. Within a good relationship, a problem within the sexual sphere was felt to have less impact because there were other positive aspects on which to focus; this facilitated positive coping strategies. A good relationship also provided a strong motive for confronting difficulties; one man (aged 30-34) for instance, described how solving his sexual difficulties became a priority once he was in a relationship that he really wanted to work.

The reaction of the partner to the problem was also important. A man with erectile difficulties described his wife's supportive attitude as one of the significant factors ameliorating his situation. In contrast, another described his wife's anger at his erectile difficulties: 
(Reaction of partner): She felt that she, as a woman, was being deprived of having sexual fulfilment and she was very angry about that. (Man aged 60-64).

A woman (aged 30-34) who had lost her desire for sex felt that to a large extent her experience was problematic because her husband saw it as such. Often a negative reaction from a partner stemmed from feelings of rejection. As the partner of a man who avoided sex (because of his erectile difficulties), one woman described feeling "pretty wretched" at first. She remembered thinking: "Well, why? Am I too plain, am I too fat, am I too ugly? Why doesn't he desire me?" (Woman aged 50-54).

Among couples with sexual difficulties (particularly erectile difficulties), the desire to conceive had the potential to aggravate the situation. For instance, one man with erectile difficulties (aged 35-39) described this as having acted as a catalyst to his seeking help, but also as a factor adding significantly to pressure to resolve the problem.

There were several accounts of sexual difficulties experienced by individuals who were without a partner at the time of interview. In general, being outside of a relationship was seen as easier because there was no one to let down:

(Partnership context): If somebody is expecting things from you which you can't give, then of course you're upset. I've got nobody to expect it from me and therefore, I've nobody to worry about but myself. (Man aged 75-79). 
At the same time, these participants recognised that these 'difficulties' might suddenly become problematic should they find themselves in a relationship.

\section{Discussion}

Our aim in writing this paper has been to explore an important gap in empirical data on coping with sexual difficulties. We hope that the resulting typology of coping strategies will be of use in assisting those coming to terms with sexual difficulties. In the same way that chronic illness has been defined as a "negotiated reality" (Strauss \& Glaser, 1975), participants in this study negotiated the meaning and significance of their experience within themselves and in response to external influences (notably their sexual partner). This negotiated reality emerged though a variety of coping strategies. We identified three over-arching strategies; changing circumstances to fit goals; changing goals to fit circumstances; and living with the gap between goal and circumstances, either by normalising one's experience or by avoiding the problem. Often a range of strategies was employed simultaneously and the mix varied over time. Choice of strategy and its success depended on several factors: the severity of the problem; the perceived causes of the problem; and the partnership context.

Our typology fits well with Brandstadter's distinction between accommodative and assimilative coping strategies (Brandstadter \& Renner, 1990). Accommodative coping involves adjusting personal preferences to fit situational constraints (what we term changing goals to fit circumstances); whereas assimilative coping strategies seek to change circumstances to fit with personal preferences (what we term changing circumstances to fit goals). Assimilation and 
accommodation represent two independent categories; the opposite of assimilation is helplessness, whereas the opposite of accommodation is rigid adherence to an unattainable goal (Skinner, Edge, Altman, \& Sherwood, 2003). Thus individuals may adopt both strategies simultaneously and both can lead to successful coping and adjustment (Boerner, 2004). Many researchers of coping behaviour believe that it is impossible to identify which coping strategies will be most successful. Depending on the problem and the context any particular strategy may be adaptive or maladaptive (Boerner, 2004). Thus it is the opposites of these strategies, rigid adherence (for example, being unable to switch to a more interpersonal version of good sex once the initial excitement of a long term relationship begins to wane) and helplessness (for example, feeling that one's sexual problems will never be cured) that are associated with less successful coping. However, where the stressful event is irreversible (such as loss of erectile function following prostate surgery) and circumstances cannot be changed, accommodative strategies are associated with better quality of life for both patients and partners (Smout, Koudstaal, Ribbers, Janssen, \& Passchier, 2001; Boerner, 2004). Thus, it seems likely that as individuals age, accommodative strategies will become increasingly important where irreversible physiological difficulties increasingly impose constraints. Indeed, it has been shown that flexibility tends to increase with age whilst tenacity declines (Smout et al., 2001). This helps explain why the decline in sexual function with age among women is not accompanied by an increase in distress (Hayes \& Dennerstein, 2005). In sum, the message of assimilative versus accommodative coping strikes resonance with a traditional prayerii: "God, give us grace to accept with serenity the things that cannot be changed, courage to change the things that should be changed and the wisdom to distinguish the one from the other". Our data however, suggest a third dimension to

\footnotetext{
ii Originally penned by Reinhold Niebuhr (1941) 'The Nature and Destiny of Man: A Christian Interpretation', The Gifford Lectures.
} 
coping responses; to acknowledge and live with a gap between goals and circumstances, either by normalising one's situation or by avoiding the problem. Although the latter in particular, may intuitively seem unlikely to lead to successful adjustment, in certain contexts, and for some individuals, it may serve as an effective strategy.

Our results provide insight into why some individuals are distressed by their sexual difficulties while others are not. We identified three factors - severity of the problem, the perceived causes of the problem, and the partnership context - as key in determining successful adjustment and in militating against distress. Previous studies support our contention that these factors are important. For instance, a nationally representative Swedish survey $(n=1056)$ found that the type and severity of the problem impacted on the level of reported distress. Among women reporting manifest difficulties (occurring quite often, nearly all the time or all the time), the proportion reporting manifest distress ranged from $72 \%$ for dyspareunia to $44 \%$ for difficulties reaching orgasm. Among those reporting mild difficulties (occurring hardly ever and quite rarely), the proportion reporting manifest distress was only 1-2\% across all the different difficulties (Öberg, Fugl-Meyer \& Fugl-Meyer, 2004). In terms of relationship context, the emotional relationship with a partner was shown to be a predictor of sexual distress in a US national survey of women (Bancroft, Loftus \& Long, 2003). And better communication with a partner about sexual needs was shown to be inversely associated with sexual distress in a postal survey of Australian women (Hayes et al., 2008). Finally, attribution has been shown to be important for adjustment to female dyspareunia (Meana, Binik, Khalife, \& Cohen, 1999), as well as other chronic conditions (see Chalder, Power, \& Wessely, 1996, for example). The relationship context is particularly important here. A recent study of provoked vestibulodynia (a female genital pain condition) 
showed that attributions made about the problem by the male partner impacted significantly on his relationship adjustment and sexual satisfaction (Jodoin et al., 2008). It is likely that the relationship between these factors and coping strategies is bi-directional; coping style, for instance, has also been shown to impact on perceived disease severity (Constant et al., 2005).

Pharmacological and biomedical interventions can offer effective treatment for only a small proportion of those who come for help with their sexual problems. Thus some of the work of health professionals, such as GPs and counsellors, involves helping individuals identify which difficulties can be ameliorated and working out ways of adapting to those that cannot. Where treatment fails or is not possible, adaptation will be much more likely where patients are encouraged towards more flexible definitions of good enough sex and flexible prioritisation of sex. Furthermore, discussion about how individuals attribute the cause of the problem, and how the interpersonal context has affected their perception of the problem and reaction to it, may provide valuable clinical information. Finally, our use of the concept of good enough sex was validated by participant descriptions of normality as less than perfect. Health professionals may find this concept helpful in discussions with patients.

There are several limitations to this study. Firstly, our sample was purposefully heterogeneous and included a disproportionate number of individuals who had experienced sexual difficulties. This is because we sought to identify the full range of coping responses, without categorising or comparing across age, gender or health status. An implication of this strategy is that the sample was weighted towards older people and those who had spent time reflecting on their sexual experiences. Qualitative methods do not aim to achieve generalisability but rather, they seek to 
identify theories and patterns with relevance to broader populations (Seale, 1999). Nevertheless, in judging the relevance of these findings to a general population, the composition of the sample needs to be borne in mind. The use of semi-structured interviews with individuals, rather than couples, also has implications for the findings. Firstly the 'lens' into the experiences of the couple was provided by only one partner; secondly the interviews could provide only a retrospective snapshot of what was in reality a dynamic and ongoing process; and thirdly, the data generated by the interviews was the product of an interaction between the interviewer and the interviewee and so approximated, rather than represented, perspectives internalised by participants themselves.

As with much qualitative work, the purpose of this study has been to generate an explanatory framework. Our typology needs to be verified quantitatively. However, our results provide important insights which may be used to assist patients for whom conventional medical treatment is not possible.

\section{References}

Arrington, R., Cofrancesco, J., \& Wu, A.W. (2004). Questionnaires to measure sexual quality of life. Quality of Life Research, 13, 1643-1658.

Balon, R. (2007). Is medicalisation and dichotomisation of sexology the answer? A commentary. Journal of Sex \& Marital Therapy, 33, 405-409.

Bancroft, J., Loftus, J., \& Long, J.S. (2003). Distress about sex: A national survey of women in heterosexual relationships. Archives of Sexual Behaviour, 32, 193-208. 
Boerner, K. (2004). Adaptation to disability among middle-aged and older adults: The role of assimilative and accommodative coping. The Journals of Gerontology Series B: Psychological Sciences and Social Sciences, 59, P35-P42.

Brandtstadter, J. \& Renner, G. (1990). Tenacious Goal Pursuit and Flexible Goal Adjustment: Explication and Age-Related Analysis of Assimilative and Accommodative Strategies of Coping. Psychology and Aging, 5, 58-67.

Bury, M. (1991). The sociology of chronic illness: A review of research and prospects. Sociology of Health and Illness, 13, 451-68.

Chalder, T., Power, M.J., \& Wessely, S. (1996). Chronic fatigue in the community: 'A question of attribution.' Psychological Medicine, 26, 791-800.

Constant, A., Castera, L., Quintard, B., Bernard, P.H., de-Ledinghen, V., Couzigou, P., \& Bruchon-Schweitzer, M. (2005). Psychosocial factors associated with perceived disease severity in patients with chronic hepatitis C: Relationship with information sources and attentional coping styles. Psychosomatics: Journal of Consultation Liaison Psychiatry, $46,25-33$.

Goldacre, B. (2007). Given the Choice, I'd Rather Have the Miracle Pill Story. British Medical Journal, 334, 932.

Green, J. \& Thorogood, N. (2004) Qualitative Methods for Health Research. London: Sage Publications.

Green, J. (2005). Analysing qualitative data. In J. Green \& J. Brown (Eds.) Principles of Social Research (pp. 76-92). Maidenhead: Open University Press

Grindle, M.S. (2007). Good enough governance revisited. Development Policy Review, 25, 553574. 
Hayes, R. \& Dennerstein, L. (2005). The impact of aging on sexual function and sexual dysfunction in women: A review of population-based studies. Journal of Sexual Medicine, 2, 317-330.

Hayes, R., Dennerstein, L., Bennett, C., Sidat, M., Gurrin, L., \& Fairley, C. (2008). Risk factors for female sexual dysfunction in the general population: Exploring factors associated with low sexual function and sexual distress. Journal of Sexual Medicine, 5(7), 1681-93

Jodoin, M., Bergeron, S., Khalifé, S., Dupuis, M., Desrochers, G., \& Leclerc, B. (2008). Male partners of women with provoked vestibulodynia: attributions for pain and their implications for dyadic adjustment, sexual satisfaction, and psychological distress. Journal of Sexual Medicine, 5, 2862-2870.

Levine, S.B. (2007). Commentary on David Rowland's "Will medical solutions to sexual problems make sexological care and science obsolete?” Journal of Sex \& Marital Therapy, 33, 449-453.

Meana, M., Binik, Y., Khalife, S., \& Cohen, D. (1999). Psychosocial correlates of pain attributions in women with dyspareunia. Psychosomatics, 40, 497-502.

Mercer, C.H., Fenton, K.A., Johnson, A.M., Wellings, K., Macdowall, W., McManus, S., Nanchahal, K., \& Erens, B. (2003). Sexual function problems and help seeking behaviour in Britain: national probability sample survey. British Medical Journal, 327, 426-7.

Metz, M.E. \& McCarthy, B.W. (2007). The 'Good-Enough Sex' model for couple sexual satisfaction. Sexual and Relationship Therapy, 22, 351-362.

Mitchell, K.R. \& Graham, C. (2008). Two challenges for the classification of sexual dysfunction. Journal of Sexual Medicine, 5, 1552-1558. 
Nazareth, I., Boynton, P. \& King, M. (2003). Problems with sexual function in people attending London general practitioners: cross sectional study. British Medical Journal, 327, 423428.

Öberg, K., Fugl-Meyer, A., \& Fugl-Meyer, K. (2004). On categorization and quantification of women's sexual dysfunctions: An epidemiological approach. International Journal of Impotence Research, 16, 261-69.

Ritchie, J. \& Lewis, J. (2003). Qualitative Research Practice: Guide for social scientists and researchers. London: Sage.

Seale, C. (1999). The Quality of Qualitative Research. London: Sage.

Skinner, E.A., Edge, K., Altman, K., \& Sherwood, H. (2003). Searching for the structure of coping: a review and critique of category systems for classifying ways of coping. Psychological Bulletin, 129, 216-269.

Smout, S., Koudstaal, P.J., Ribbers, G.M., Janssen, W.G.M., \& Passchier, J. (2001). Struck by stroke: a pilot study exploring quality of life and coping patterns in younger patients and spouses. International Journal of Rehabilitation Research, 24, 261-268.

Strauss, A. (1987). Qualitative Analysis for Social Scientists. New York: Cambridge University Press.

Strauss, A. \& Glaser, B. (1975). Chronic illness and quality of life. St. Louis: C.V. Mosby and Co.

Swain, P.A. \& Cameron, N. (2003). 'Good Enough Parenting': Parental disability and child protection. Disability and Society, 18, 165-177. 